\title{
Urinary Albumin Excretion and Cardiovascular Risk in Nondiabetic Middle-Aged Adults : the 2011-2012 Korean National Health and Nutrition Examination Survey
}

\author{
Jin Hwa Kim, Hee Jung Ahn, Sang Yong Kim
}

Department of Endocrinology and Metabolism, Chosun University Hospital, Gwangju, Republic of Korea

\section{OBJECTIVES}

Microalbuminuria is known as a predictor of cardiovascular disease (CVD) in patients with and without diabetes, as well as the general population. Recent studies have suggested that high normal albuminuria levels also indicate an increased risk of CVD in the general population. The objective was to determine whether there was an association between the urinary albumin excretion and CVD risk by estimating the Framingham Risk Score (FRS) in nondiabetic middle-aged adults.

\section{METHODS}

This study was based on data from the Korea National Health and Nutrition Examination Survey (KNHANES), which was conducted by the Korean Ministry of Health and Welfare in 2011-2012. From the 16,576 participants, data for 5,165 adults who were 40-79 years of age were included in the analysis. Based on the urinary albumin to creatinine ratio (UACR), the subjects were categorized into normal ( $\leq 9.9 \mathrm{mg} / \mathrm{g}$ ), high normal $(10.0$ to $29.9 \mathrm{mg} / \mathrm{g})$, and microalbuminuria (30.0 to $299.9 \mathrm{mg} / \mathrm{g}$ ) groups.
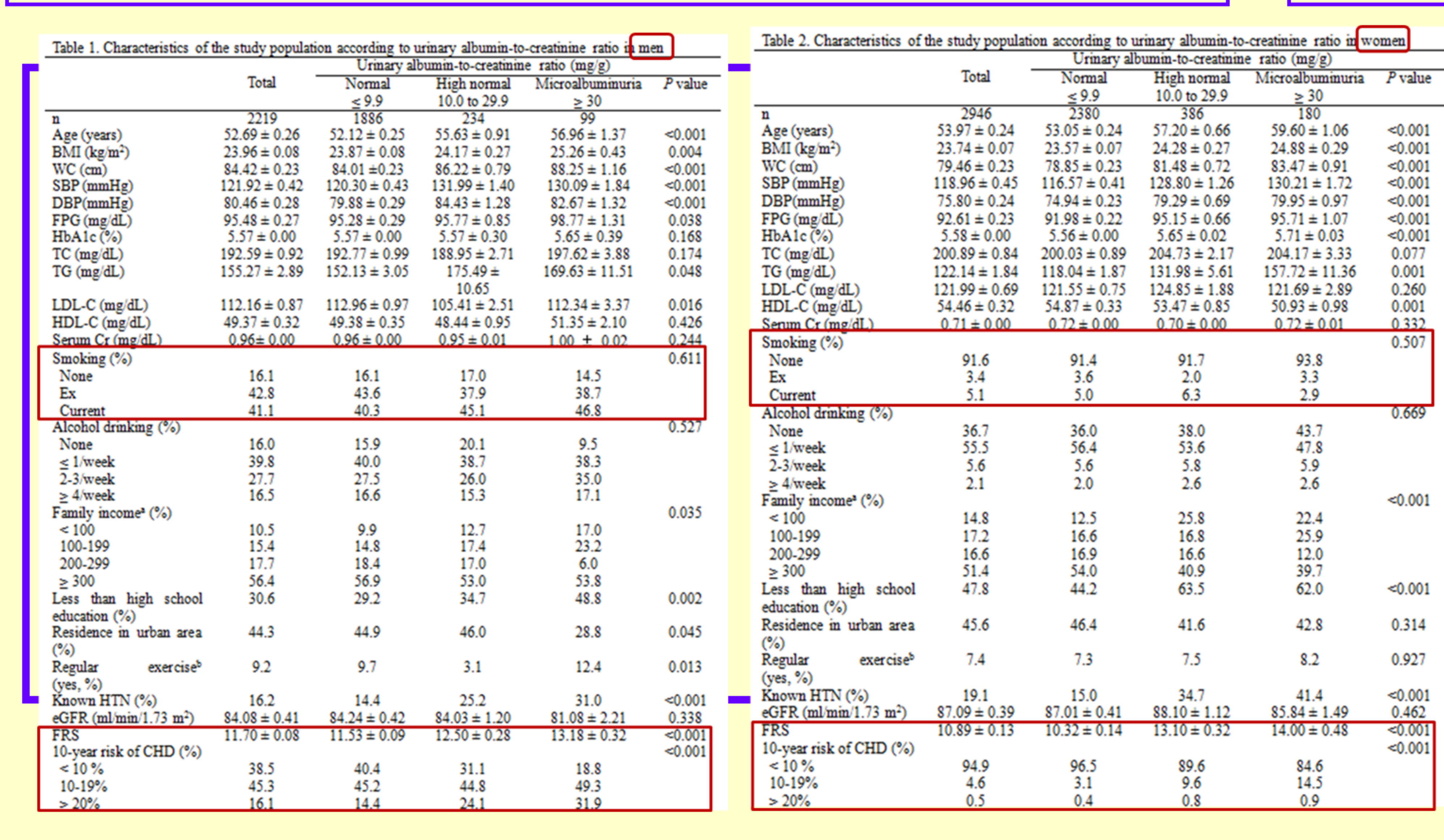

Table 3. Odds ratio( $95 \% \mathrm{Cl}$ ) for $\geq 20 \% 10$-year risk of

Coronary heart disease according to urinary albumin to creatinine ratio in man Normal $\quad$ High nomal $\quad$ Microalbuminuria

\section{Model 1}

Model 2

Model 3 Model 4

Table 4. Odds ratio(95\% Cl) for $\geq 10 \% 10$-year risk of

Coronary heart disease according to urinary albumin to creatinine ratio in woman

\section{RESULTS}

The mean FRS was significantly different in each of the UACR subgroups, and it increased with increases in the UACR: $11.53 \pm 0.09$ in the normal, $12.50 \pm 0.28$ in the high normal, and $13.18 \pm 0.32$ in the microalbuminuria in men; $10.32 \pm 0.14$ in the normal, $13.10 \pm 0.32$ in the high normal, and $14.00 \pm 0.48$ in the microalbuminuria in women. After fully adjusting for potential confounding factors, including lifestyle, sociodemographic factors, known CVD risk factors, and eGFR, high normal levels and microalbuminuria were significantly associated with $\geq 10 \% 10$ year risk of CVD (odds ratio [OR] 1.777, 95\% confidence interval [CI], 1.216-2.597] and OR 2.232 [1.197-4.160], respectively) compared with the normal subgroup in men. High normal levels and microalbuminuria were also significantly associated with $a \geq 10 \%$ 10-year risk of CVD (OR 2.041 [1.173-3.550] and OR 3.115 [1.538-6.308], respectively) after adjusting for the above covariates in women.

\section{CONCLUSIONS}

Urinary albumin excretion reflects CVD risk in middle-aged adults without diabetes, and high normal levels and microalbuminuria were independently associated with a higher risk of CVD.

We propose that urinary albumin excretion may reflect the CVD risk in middle-aged adults without diabetes and that it should be considered a risk factor for CVD.

To effectively prevent CVD in middle-aged adults without diabetes, more attention should be focused on middle-aged adults with microalbuminuria and even those with higher albuminuria levels that are within the normal range.

\section{References}

1. de Zeeuw D, Parving $H H$,
Henning RH. Microalbuminuria as
an early marker for cardiovascular
disease. J Am Soc Nephrol
$2006 ; 17: 2100-5$.
2. Gerstein HC, Mann JF, Yi
$\underline{Q}, \underline{\text { Zinman } B}, \underline{\text { Dinneen }}$
$\underline{\text { SF, Hoogwerf B et al. Albuminuria }}$
and risk of cardiovascular events,
death, and heart failure in diabetic
and nondiabetic individuals. JAMA
2001;286:421-6

1. de Zeeuw D, Parving $\mathrm{HH}_{\text {, }}$ Henning RH. Microalbuminuria as n early marker for cardiovascula disease. J Am Soc Nephrol

$\underline{\mathrm{SF}}, \underline{\mathrm{Hoogwerf} B}$ et al. Albuminuria death, and heart failure in diabetic and nondiabetic individuals. JAMA 